\title{
Water resources of Pakistan: An analysis of sources and situation
}

\author{
Mushtaque Ahmed Pathan ${ }^{1 *}$ and Maryam Maira Pathan ${ }^{2}$ \\ ${ }^{1}$ Center for Pure \& Applied Geology, University of Sindh, Jamshoro, Pakistan \\ ${ }^{2}$ Institute of Environmental Engineering \& Mgmt Mehran University of Engineering \& Technology, \\ Jamshoro, Pakistan
}

Water assets are turning into an incredible issue everywhere in the world, there are numerous reasons the natural issues are one of the significant causes. Pakistan isn't liberated from a similar danger of diminishing water assets on the surface and subsurface. The regular purposes behind precipitation like a downpour and icy mass dissolving are two primary sources that can add the surface and underground water.

The powerful Indus waterway is just uber wellspring of giving water, this stream is additionally partitioned in little five streams entering the Punjab region in Pakistan prompting Sindh area and is called INDUS Stream (SINDHU NADI) in Sindhi language, at long last the stream falls in the Indus Sea (INDIAN Sea) at Karachi through Indus delta at a spot known as Jati Region Thatta Sindh Pakistan. Despite having a greater number of glacial masses than elsewhere on the planet and its area in the Indus Stream Bowl, Pakistan is in danger of intense water shortage. Its surface and groundwater sources are both progressively troubled and awful dry spell conditions exist in pieces of the nation because of an absence of downpour. Additionally, Pakistan has a tremendous agribusiness area, which uses rising water for the water system to develop waterescalated crops. The water conveyance framework in Pakistan is obsolete and in helpless condition, which is the reason for squandering significantly more water, while little is put away on the grounds that practically no repositories and residue statement in existing water offices. The remainder of accessible water that is generally messy, having been contaminated by human, agrarian, and modern waste [3].

Pakistan, when a water-surplus nation, is presently a water shortfall country. The precipitation is neither adequate nor customary, to meet the developing necessities of water.
Around $70 \%$ of the yearly precipitation happens in the long stretches of July to September. The surface water assets of Pakistan chiefly comprise streams of the Indus River and its feeders, which achieve 138 million sections of land feet (MAF) of water yearly. The Indus River alone gives $65 \%$ of the absolute waterway streams, while the portion of Jhelum and Chenab is 17 and $19 \%$ individually. The long periods of pinnacle stream are June to August during the rainstorm season. The stream during the Kharif (Summer) is $84 \%$ and during Rabi (Winter) season is $16 \%$. The alluvial fields of Pakistan are honored with broad unconfined spring, with a capability of more than 50 MAF, which is being misused to a degree of around 38 MAF by more than 562,000 private and 10,000 public tubewells. In Balochistan (outside the Indus Basin), out of a complete accessible capability of about 0.9 MAF of groundwater, over 0.5 MAF are as of now being used, in this way leaving an equilibrium of about 0.4 MAF that can, in any case, be used, however, a few springs are now over misused.

The issue is duplicated by helpless administration and the board in the water area. While the laws overseeing water, they are regularly abused by nearby persuasive people with unlawful collaboration of administration. While the appropriation of the Public Water Strategy in 2018 has been a reason for idealism in Pakistan, it's unclear and some of the time opposing phrasing raise worries that the nation's water emergency will keep on deteriorating.

The more terrible province of Pakistan's water assets achieved global consideration in 2018 because of the notion that the nation could confront water shortage by 2025. Pakistan's two significant dams, the Tarbela and Mangla Dams, both contacted or moved toward their dead stockpiling levels more than one time, showing further disturbing circumstances [2]. 
The significant wellsprings of water in Pakistan, are considered as precipitation, frigid overflow, waterways, and groundwater. In which around $60 \%$ of precipitation comes from storm drains, a critical extent is conveyed during winter (December to Spring) climate designs. Because of the different geology of Pakistan, precipitation will in general shift essentially from one district to another. A large part of the nation's land is parched or semi-bone-dry, with 3/4 of Pakistan getting under 250 millimeters of downpour each year and dry seasons are normal in numerous spaces.

In Sindh and Balochistan, genuine dry spell conditions have been brought about by an absence of downpour throughout the colder time of year and storm precipitation periods. An investigation by the Assembled Countries Advancement Program recommended that while more examination should be done on the effects of environmental change on precipitation in Pakistan, patterns throughout the last 25 to 50 years propose that precipitation has diminished in Balochistan and including waterfront regions despite the fact that it has expanded on normal in certain pieces of the country in Punjab and northern territories. The pace of snow soften has additionally been influenced by environmental change, making a more serious danger of flooding and outrageous water cycle change. Snowmelt and chilly overflow additionally contribute somewhere in the range of 30 and 40 percent and 30 to 35 percent of Indus waterway streams, individually, making their commitment fundamental to Pakistan's hydrological cycle.

The Indus Stream framework contains generally surface and groundwater assets of Pakistan. In 1950, surface water accessibility per capita was 5,260 cubic meters for each individual. By 2016, that had tumbled to near $1,000 \mathrm{~m}^{3}$, a pattern that is required to proceed. Groundwater extraction rates are additionally of extraordinary concern. In all areas of Pakistan at present concentrates around 60 cubic kilometers of water from its springs every year, which far surpasses supportable cutoff points. and water-scant (low water accessibility per capita). The circumstance is exacerbated by Pakistan's pace of water use - the fourth-most noteworthy on the planet - while its water power rate (the measure of water utilized per unit of Gross domestic product) is the most elevated on the planet. This proposes that Pakistan's economy is more water-serious than some others [1].

The Indus River System, accordingly, won't proceed with independence in horticultural creation. Because of huge measures of silt got by the taking care of waterways, the three significant repositories - Tarbela, Mangla, and Chashma - will lose their capacity limit, by $25 \%$ before the year's over 2010, which will additionally exasperate the wateraccessibility circumstance. This paper assesses the current circumstance of water assets, present necessities, and future prerequisites, the difficulties forced and recommends short, medium, and long haul systems to adapt to the circumstance. The proposed momentary techniques incorporate beginning a mass-mindfulness crusade, the proliferation of highproductivity water system frameworks, changes in editing designs, recognizable proof of practical surface-water stockpiling locales and dams, and actuation of water-client associations. The medium-term methodologies propose offering need to the coating of distributaries, minors, and streams in saline groundwater territories, development of little dams and establishment of tubewells in fact possible zones, improving flood and drought forecasting techniques, and a lot more extensive use of conjunctive water-use approach and engendering of high-effectiveness water system frameworks. Institutional changes for better coordination and a more extensive detailing of a public water strategy are other need regions under the medium-term key arrangement. Longterm procedures remember the definition of an administrative system for groundwater reflection, development of huge stockpiling dams, better flood and dry season gauging instruments, and settling water-appropriation issues between areas. It is suggested that a National Commission on Water, upheld by a specialists board, be made to guide the detailing of the techniques and guarantee the execution of the procedures proposed. Presentation is fundamental for supporting personal satisfaction on earth. This limited product has an immediate bearing on practically all areas of the economy. In Pakistan, its significance is more than standard because of the agrarian idea of the economy. The portion of rural area in the Gross Domestic Product (GDP) of Pakistan is around $24 \%$. Since agribusiness is the significant client of water, thusly maintainability of farming relies upon the ideal and sufficient accessibility of water. The expanding pressing factors of populace and industrialization have effectively positioned more prominent requests on water, with an ever-increasing number and force of nearby and provincial struggles over its accessibility and use. Generally, the high aridity list of the nation is adding further to the meaning of water informative exercises in Pakistan. However, when a water-surplus country with immense water assets of the Indus River System, Pakistan is presently a waterdeficiency country. As of now, the yearly per capita wateraccessibility in Pakistan is around 1,100 cubic meters (m3); under $1,000 \mathrm{~m} 3$, nations start encountering persistent water pressure (Population Action International, 1993). Table gives the correlation of per-capita water.

Surface Water-Resources Surface-water assets of Pakistan are principally founded on the progressions of the Indus River and its feeders. The Indus River has a complete length of 2900 kilometers $(\mathrm{Km})$ and the seepage region is around 966,000 sq. Km. Five significant feeders joining its eastern side are Jhelum, Chenab, Ravi, Beas, and Sutlej; moreover, three minor feeders are the Soan, Harrow, and Siran, which channel in bumpy zones. Various little feeders additionally join the Indus towards its western side. The greatest of such feeders is River Kabul. Waterways in Pakistan have singular stream attributes, however, every one of them, for the most part, begins to ascend in the spring and late spring, with the rainstorm rains and snow softening on the mountains and have a consolidated pinnacle release in July and August. The streams are least during winters e.g., during the time frame November to February, mean month to month streams are just around one 10th of those in summer. Other than the significant waterways, there are various little streams and streams, which are just occasional with streams contingent upon downpour fall and convey for all intents and 
purposes no water throughout the cold weather months. also, convey basically no water throughout the cold weather months. The 77-year record of the Indus River (1922-23 to 1999-2000) demonstrates that the watersheds of the Indus River yield.

To deal with these degrees of water pressure and shortage much have as of late been made by the Pakistani Government about an overall absence of enormous dams and supplies in the country. While the group subsidizing techniques embraced by the public authority to construct new dams are ridiculous, the restricted capacity limit has likewise added to expanded water shortage. Pakistan has as long as 30 days of capacity limit, which not just restricts the measure of water accessible during the dry season, yet in addition adds to flooding during wet seasons, as there are not many dams to assimilate the overabundance of water. A lot of Pakistan's high water use originates from its to a great extent agrarian economy. Just about $70 \%$ of the populace is straightforwardly or by implication utilized in the farming area, which represents $26 \%$ of its total national output. Pakistani ranchers develop 21.2 million hectares of land, of which more than $80 \%$ is watered. Cultivating is overwhelmed by four water-serious yields: wheat, sugarcane, rice, and cotton. Accordingly, 93\% of the water devoured in Pakistan is utilized for agribusiness (the worldwide normal is nearer to around $70 \%$ ). While Pakistan's water system framework is huge, it is obsolete and ineffectively kept up. Specifically, quite a bit of Pakistan's farming is reliant on floodwater system techniques, which includes flooding fields utilizing channels or cylinder wells. A significant number of the streams that convey water from waterways for this technique for water system are not suitably lined, prompting further drainages of up to 40 percent.

Concentrated water system likewise has suggestions for Pakistan's groundwater supply, as an absence of dependable surface water has made ranchers progressively depend on groundwater. Of the water utilized for the water system, roughly half comes from springs, to some degree, since it isn't dependent upon occasional accessibility. While it is a helpful water source, an increment in siphoning is ongoing for many years has prompted a huge decrease in groundwater tables, particularly in Punjab and Sindh, where agribusiness is the broadest. Unchecked groundwater deliberation has added to the Indus Bowl spring turning into the second-generally focused on the planet, as indicated by an investigation led somewhere in the range of 2003 and 2013 [3].

Alongside actual boundaries to water security, water governmental issues have additionally exacerbated the emergency. Because of frontier period water laws and an absence of genuine administration, Pakistan's water approaches have come to be overwhelmed by three primary factors: a reliance on progressively bygone laws and structures; a solid inclination for huge scope designing undertakings to tackle water issues (the new drive to construct two enormous dams, notwithstanding concerns, is a commonplace model); and approximately characterized water rights. Much of the time, land possession characterizes who has a privilege to water. Quite a bit of Pakistan's water framework is likewise in a helpless condition, Pakistan's water assets are overseen at a common level, representing another predicament for water executives. Between common questions have ruled the discussion on water change. Albeit the 1991 Water Accord relieved some commonplace worries (by distributing water to territories dependent on a specific equation) the arrangement of execution, which is managed by the Indus Stream Framework Authority (IRSA), is missing and it is extremely unlikely to screen streams in case of a question. Reactions of the IRSA has expanded in the course of the most recent decade because of its powerlessness to deal with the requirements, all things considered, which has been brought about by the continuous decrease in water streams [4].

Pakistan's water assets are overseen at a common level, representing another issue for water the executives. Between common questions have ruled the discussion on water change. Albeit the 1991 Water Accord relieved some commonplace worries (by distributing water to territories dependent on a specific recipe) the arrangement of execution, which is supervised by the Indus Stream Framework Authority (IRSA), is missing and it is extremely unlikely to screen streams in case of a debate. Reactions of the IRSA have expanded throughout the most recent decade because of its failure to deal with the requirements, everything being equal, which has been brought about by the continuous decrease in water streams. Different endeavors at change have made various offices with covering obligations and duties, making wasteful administration and further decreasing the chance of good water administration [5].

\section{References}

1. Ali G, Hasson S, Khan AM (2009) Climate change: Implications and adaptation of water resources in Pakistan. Global Change Impact Studies Centre (GCISC): Islamabad, Pakistan. Link: https://bit.ly/3tZg9sn

2. Ahmad S (2007) Land and water resources of Pakistan-A critical assessment Pakistan Development Review 46: 911-937. Link: https://bit.ly/2R3q7dN

3. Kahlown MA, Majeed A (2003) Water-resources the situation in Pakistan: challenges and future strategies. Water Resources in the South: present scenario and future prospects 20: 33-45. Link: https://bit.ly/3vptGcT

4. Sleet P (2019) Water Resources in Pakistan: Scarce, Polluted and Poorly Governed. Independent Strategic Analysis of Australia's Global Interest. Nedlands 2. Link: https://bit.ly/3sU1Jsh

5. Kahlown MA, Majeed A (2003) Water-resources the situation in Pakistan challenges and future strategies. Water Resources in the South: present scenario and future prospects 20: 33-45. Link: https://bit.ly/3vptGcT

Citation: Pathan MA, Pathan MM (2021) Water resources of Pakistan: An analysis of sources and situation. Ann Environ Sci Toxicol 5(1): 027-029. 